\title{
Boar presence reduces fighting in mixed slaughter-weight pigs
}

\author{
T. Grandin and J. Bruning \\ Department of Animal Sciences, Colorado State University, Fort Collins, CO 80523, USA
}

(Accepted 30 August 1991)

\begin{abstract}
Grandin, T. and Bruning, J., 1992. Boar presence reduces fighting in mixed slaughter-weight pigs. Appl. Anim. Behav. Sci., 33: 273-276.

Mixing pigs prior to slaughter results in skin blemishes and loss of meat quality. Two hundred pigs each weighing $104 \mathrm{~kg}$ were used in two trials. They were crosses of Hampshire, Duroc and Yorkshire which had been fed to slaughter weight on ad libitum concentrate rations. Groups of 50 head of barrows and gilts from five different feeding pens were mixed in a shipping pen prior to transport. Half the animals were mixed with sexually mature boars, and the other half were controls. Boar presence greatly reduced both the incidence and the intensity of fighting. Pigs from the boar groups had reduced skin blemishes. These results indicate that boars may be used as a simple method to reduce fighting.
\end{abstract}

\section{INTRODUCTION}

Fighting between newly mixed pigs may cause severe injuries in slaughterweight pigs. Guise and Penny (1989) found that mixing slaughter-weight pigs at the farm prior to loading resulted in more skin damage than mixing at the abattoir. Observations by one of the authors (Grandin) indicated that mixing small groups of five to eight limit-fed pigs in shipping pens at the farm resulted in severe skin damage from biting. A high percentage of fights occur within 30 min of mixing (Moss, 1978). Ideally, pigs should be penned on trucks and at the abattoir with penmates from the farm. Unfortunately, this is not always possible, especially in American abattoirs that slaughter over 7000 pigs on a single 8 -h shift.

There is a need for a simple economical method to reduce fighting in newly mixed slaughter-weight pigs. Fighting causes economic losses to the industry

Correspondence to: T. Grandin, Department of Animal Sciences, Colorado State University, Fort Collins, CO 80523, USA.

(C) 1992 Elsevier Science Publishers B.V. All rights reserved 0168-1591/92/ $\$ 05.00$ 
and it is detrimental to pig welfare. Stress and exertion during fighting can increase the incidence of both PSE (pale soft exudative) and DFD (dark firm dry) meat (Grandin, 1985; Warriss and Brown, 1985; Guise and Penny, 1989). Damage caused by fighting has been a major impediment to the development of the pig skin leather industry. Abattoirs that installed pig skinning equipment found that they could not market skins with bite marks.

Previous research has shown that a variety of methods will reduce fighting. Placing hanging cloth strips in the pen where pigs are mixed will reduce fighting Grandin, 1989). Kelly et al. (1980) found that placing straw in the pens had a tendency to reduce fighting in fasted pigs. The two most effective methods for reducing fighting cause problems with the regulatory authorities, Azaperone and androsterone: injections of the sedative Azaperone greatly reduce fighting, but in many countries, the use of sedatives is forbidden in slaughterweight pigs due to residue problems. A study by Symoens and van den Brande (1969) determined that the sedative reduced fighting by more than half. Another highly effective method is spraying pigs with androsterone immediately after mixing. This resulted in 58\% less time engaged in aggressive behavior (McGlone et al., 1986). McGlone (1988) states that aerosolized androsterone is more effective than the sedative Azaperone and Amperozide. Androsterone is a natural substance that is present in the saliva and fat of boars. Very small concentrations of this substance will inhibit fighting (McGlone and Morrow, 1988). Even though this substance is natural, the extract is classified as a drug by many regulatory authorities. Marketing of androsterone to pork producers has been hampered because the drug approval process is very expensive.

The purpose of this experiment was to determine if mixing strange slaughter-weight pigs in the presence of intact sexually mature boars would reduce fighting. This would provide a simple economical method to greatly reduce fighting which could be quickly put into practice by pork producers.

\section{ANIMALS, MATERIALS AND METHODS}

The pigs used in this experiment originated from a farm using three-breed rotational crossbreeding composed of Hampshire, Duroc and Yorkshire breeds. These commercial crossbred pigs were grouped together for 14 weeks in groups of 17-20. They were intensively confined in buildings with two curtained sides. The pigs were fed a standard American corn and soybean meal diet ad libitum from self feeders, to the slaughter weight of $104 \mathrm{~kg}$, at which time they were sorted.

In Treatment I, groups of 50 slaughter-weight pigs were sorted from five pens. As a result of commercial restraints, varying numbers of pigs were taken from the five pens. The pigs were then immediately driven into a $3 \times 16 \mathrm{~m}$ roofed pen with one partially open side, where they were assembled prior to shipping. Treatment I groups were observed for $50 \mathrm{~min}$ for fighting behavior. 
After observation, each animal was wound-scored 'yes' or 'no', based on the presence of visible wounds.

In the Treatment II groups, three young, sexually mature, 204-kg Hampshire boars which had been previously housed together were introduced to the pen 10 min prior to the entry of 50 head of newly sorted slaughter-weight pigs. Treatment II groups were also observed for $50 \mathrm{~min}$, and wound-scored in the same manner as in Treatment I.

Two trials of each treatment were conducted on two separate days, 20 days apart. In both trials, Treatment I groups were mixed and observed prior to Treatment II groups so as not to have 'boar scent' present in the pen. A total of 200 slaughter-weight pigs were used for this experiment. The same three Hampshire boars were used in both Treatment II groups. The weather during both trials was clear and the temperature was between $-10^{\circ} \mathrm{C}$ and $13^{\circ} \mathrm{C}$.

The one/zero sampling method (Lehner, 1979) was used to tabulate fighting every $60 \mathrm{~s}$, with 50 possible segments per treatment for each trial. The Chi-square test was used to determine significance.

\section{RESULTS}

In both trials, Treatment II pigs (mixed with three boars) had reduced fighting compared to Treatment I pigs. Using the one/zero sampling method, the following results were determined. In Treatment I pigs, there were 41 segments with fighting in Trial 1, and 41 segments of fighting in Trial 2. For the Treatment II pigs, the results were 14 segments with fighting in Trial 1 pigs and 20 segments of fighting in the Trial 2 pigs. For the combined trials, $\chi^{2}=47.3(P<0.001)$.

Wound scores were recorded for both treatments in both trials. Wounding was reduced in the pigs mixed with the three boars. In Trial 1 Treatment I, 16 pigs were wounded compared with two pigs in the Treatment II group. In Trial 2 Treatment I, there were 11 wounded pigs, whereas in Treatment II, only three pigs were wounded. $\chi^{2}$ for the combined trials is $18(P<0.001)$.

\section{DISCUSSION}

Mixing slaughter-weight pigs in the presence of sexually mature boars greatly reduced fighting. Observations indicated that the few fights that occurred in the presence of boars were less intense. This observation is not fully reflected in the numerical results because a fight was counted regardless of intensity. The boars did not attempt to mount any of the prepubertal gilts. Boars did not attack the pigs except for a minor incident where a pig repeatedly attacked a boar. The boars never damaged any of the pigs. The pigs displayed submissive behavior when a boar approached. They moved out of the way and stopped fighting when the boar was nearby. 
The use of boars to prevent fighting is a practical method to reduce fighting in castrate and gilt slaughter-weight pigs. A large swine farm in the midwestern United States has resident boars that live in their shipping pens. Use of the boars has also provided an added benefit of reducing shrink. Observations by the swine farm manager indicated that boars sometimes intervene and stop fights. He also learned that he had to use the right boars: some boars could not be used because they had a very high sex drive.

In our experimental pigs, a boar was observed walking between two fighting pigs. Further research will be needed to determine the effect of mature boar presence on prepubertal boar pigs and on mixed weaned sows. Fighting between newly mixed sows is a major welfare problem. Possibly, boar presence either in the mixing pen or in an adjacent pen could reduce fighting in gestating sows.

\section{ACKNOWLEDGEMENTS}

We wish to acknowledge the cooperation of Comanche Livestock Company in Strasburg, CO, for the use of their pigs and facilities. The authors wish to thank Loren Losh and Chris Losh for their assistance with this project.

\section{REFERENCES}

Grandin, T., 1985. Improving pork quality handling systems. Anim. Health Nutr., July-Aug, 41: 14-26.

Grandin, T., 1989. Effect of rearing environment and environmental enrichment on the behavior and neural development of young pigs. Dissertation, University of Illinois, Champaign/ Urbana, IL, USA.

Guise, H.J. and Penny, R.H.C., 1989. Factors influencing the welfare and carcass and meat quality of pigs. Anim. Prod., 49: 517-521.

Kelly, K.W., McGlone, J.J. and Gaskins, C.T., 1980. Porcine aggression: measurement and effects of crowding and fasting. J. Anim. Sci., 50: 336-341.

Lehner, P.N., 1979. Handbook of Ethological Methods. Garland Press, New York.

McGlone, J.J., 1988. Olfactory signals that modulate pig aggressive and submissive behavior. In: R. Zayan and R. Dantzer (Editors), Social Stress in Domestic Animals. Kluwer, London, pp. 86-108.

McGlone, J.J. and Morrow, J.C., 1988. Reduction of pig antagonistic behavior by androsterone. J. Anim. Sci., 66: 880-884.

McGlone, J.J., Stansbury, W.F. and Tribble, L.F., 1986. Aerosolized 5 $\alpha$-androst-16-in-3-one reduced agonistic behavior and temporarily improved performance of growing pigs. J. Anim. Sci., 63: 679-684.

Moss, B.W., 1978. Some observations on the activity and aggressive behavior of pigs when penned prior to slaughter. Appl. Anim. Ethol., 4: 323-339.

Symoens, J. and van den Brande, M., 1969. Prevention and cure of aggressiveness in pigs using the sedative Azaperone. Vet. Rec., 85: 64-67.

Warriss, P.D. and Brown, S., 1985. The physiological responses to fighting in pigs and the consequences for meat quality. J. Sci. Food Agric., 36: 87-92. 